\title{
Pemanfaatan Daun Kemuning Sebagai Obat Tradisional Penyakit Asma
}

\author{
Riska Nanda Elvina Safitri, Mustika Elmi Dayana, Vinna Chientya Nur Annissa, \\ Dita Aulia, Dewi Jumiarni* \\ Program Studi Pendidikan Biologi Universitas Bengkulu \\ *E-mail: dewij@unib.ac.id \\ DOI: https://doi.org/10.33369/pendipa.4.3.27-31
}

\begin{abstract}
Kemuning (Murraya paniculata L) is a shrub growing in tropical climates and wildly in bushland or forest. The local people of Serawai ethnic in Bengkulu often use kemuning leaves as a traditional medicine for asthma disease. This research was a descriptive study by using interview method with purposive sampling techniques. Respondence samples of this study were five traditional medicine healer. This study aims to analyze the potential and benefits of Kemuning (Muraya paniculata L) leaves as a traditional medicine for asthma disease. The results found that the plant parts that are used as an asthma medicine that is the leaf organs by processing squeezed, filtered, smeared and drunk. Kemuning leaves have the potential to be developed as an asthma medicine, but further research needs to be conducted before used in pharmaceutical industry.
\end{abstract}

Keywords: Kemuning leaves, astma, traditional medicine, Serawai ethnic.

\begin{abstract}
ABSTRAK
Kemuning (Murraya paniculata L) merupakan tanaman perdu yang tumbuh di daerah yang beriklim tropis dan tumbuh liar di semak belukar atau hutan. Masyarakat suku serawai di Kecamatan Sukaraja Kabupaten Seluma, Bengkulu sering memanfaatkan daun kemuning sebagai obat tradisional bagi penyakit asma. Penelitian ini merupakan jenis penelitian deskriptif menggunakan metode wawancara dengan teknik purposive sampling. Sampel yang diwawancarai berjumlah lima orang yang merupakan pengobat tradisional (dukun). Penelitian ini bertujuan menganalisis potensi dan manfaat daun kemuning (Muraya paniculata L) dalam penyembuhan penyakit asma. Hasil penelitian ditemukan bahwa bagian tumbuhan yang dimanfaatkan sebagai obat asma yaitu pada organ daun dengan cara pengolahan diremas, disaring, diminum dan dioleskan. Daun kemuning berpotensi dikembangkan sebagai obat asma, namun perlu dilakukan penelitian lebih lanjut sebelum dapat digunakan dalam industri farmasi.
\end{abstract}

Kata kunci: Daun kemuning, asma, obat tradisional, suku Serawai.

\section{PENDAHULUAN}

Indonesia merupakan negara dengan biodiversitas tertinggi kedua setelah Brazil. Kekayaan ini meliputi flora dan fauna yang tersebar diseluruh wilayah Indonesia. Flora di indonesia menempati urutan ke tujuh di dunia dengan spesies mencapai 20.000 spesies. Dengan kekayaan flora yang ada di Indonesia secara langsung maupun tidak langsung berpengaruh terhadap kehidupan masyarakat nya. Salah satunya, masyarakat memanfaatkan tumbuhan yang ada di sekitarnya sebagai obat - obatan. Sejak dulu,

Indonesia memiliki pengetahuan tentang penggunaan tanaman sebagai obat tradisional yang diwariskan secara turun- temurun.

Pemanfaatan tumbuhan sebagai obat masih dilakukan oleh masyarakat di suku 
Serawai, kecamatan Sukaraja, Bengkulu. Sejak dahulu, masyarakat suku Serawai ini telah banyak memanfaatkan tumbuhan sebagai bahan pengobatan berbagai macam penyakit. Pemanfaatkan tumbuhan obat ini dilakukan karena masyarakat memiliki pengetahuan tentang pengobatan tradisional. Selain itu, keanekaragaman tumbuhan yang tinggi didaerah ini juga melatarbelakangi pemanfaatan tumbuhan sebagai obat tradisional.

Kecamatan Sukaraja merupakan salah satu kecamatan yang ada di wilayah Seluma Barat, kabupaten Seluma, provinsi Bengkulu yang memiliki beragam suku salah satu yaitu Serawai. Suku Serawai merupakan suku mayoritas yang terdapat di daerah Seluma dan merupakan suku asli kabupaten Seluma (portal selumakab.go.id).

Asma berasal dari bahasa Yunani yaitu asthma yang artinya sulit bernapas. Penyakit asma adalah peradangan saluran napas kronik dengan indikasi adanya mengi, batuk, dan rasa sesak yang timbul berulang terutama saat malam atau menjelang pagi karena adanya penyum-batan pada saluran pernapasan (Global intiative for atshama, 2011). Penyakit ini banyak diderita oleh masyarakat mulai dari tingkatan ringan, sedang dan berat. Penderita asma setiap tahunnya cenderung meningkat, berdasarkan data WHO (2002), diperkirakan terdapat 300.000 .000 orang menderita asma dan diprediksikan jumlah ini akan meningkat mencapai 400.000.000 pada tahun 2025 diseluruh dunia. Penyebab meningkatnya penyakit asma dikarenakan kualitas udara yang buruk dan pola hidup yang berubah. Asma menyebabkan inflamasi pada saluran pernafasan yang membuat saluran pernafasan lebih hiperesponsif sehingga dapat menyebabkan bronkokonstriksi, edema, dan sekresi kelenjar berlebihan yang dapat menghambat aliran udara di saluran pernafasan sehingga menghasilkan gejala klinis berupa mengi, sesak napas, dada terasa berat dan alergi.

Tumbuhan kemuning masuk kedalam tumbuhan perdu yang bercabang dan beranting banyak. Batangnya keras beralur dan tidak berduri. Daunnya majemuk dengan helaian daun berbentuk oval. Bunga kemuning majemuk dan berbentuk tandan terdiri dari 1-8 bunga. Warna bunga putih dan harum. Buah kemuning berbentuk bulat telur dengan panjang 8 - $12 \mathrm{~mm}$, buah berwarna hijau ketika muda dan menjadi merah mengkilap ketika tua. Didalam buah terdapat biji (Iskandar, 2005). Adapun klasifikasi kemuning menurut Hembing (2000) adalah:

$\begin{array}{ll}\text { Kingdom } & \text { : Plantae } \\ \text { Divisi } & \text { : Magnoliphyta } \\ \text { Kelas } & \text { : Magnoliopsida } \\ \text { Ordo } & \text { : Sapindales } \\ \text { Family } & \text { : Rutaceae } \\ \text { Genus } & \text { : Murraya } \\ \text { Spesie } & \text { :Murraya paniculata L. Jack }\end{array}$

Tumbuhan kemuning atau (Muraya paniculata L) merupakan tumbuhan perdu tumbuh liar disemak belukar ataupun dihutan dan tumbuh secara luas dikawasan Asia Tenggara, Cina bagian selatan, Taiwan, India, dan kepulauan Okinawa (Kinoshita et al., 1989). Tumbuhan yang termasuk dalam family Rutaceae ini telah dimanfaatkan sebagai obat tradisional, diantaranya anti inflamasi dan penghilang bengkak. Tumbuhan ini diketahui memiliki kandungan senyawa turunan kumarin yang dapat menghambat pelepasan histamin dari sel sehingga dapat dijadikan sebagai anti 
inflamasi. Senyawa kumarin ini diantaranya yaitu aurapten, gleinadien, coumurrayin, toddalenon, 5-methoxymurrayin, sibiricin dan metoxicin (Kinoshita et al., 1996). Bagian tanaman ini yang biasa digunakan dalam pengobatan adalah daun, kulit batang, maupun buahnya (Kong, et al., 1986).

Pengetahuan tentang pemanfaatan daun kemuning sebagai obat tradisional asma oleh suku Serawai di kecamatan Sukaraja hanya berdasarkan data empiris yang diwariskan secara turun menurun secara lisan. Data ini merupakan informasi awal yang sangat penting untuk pengembangan obat modern, terutama dalam upaya mencari sumber bahan obat-obatan baru yang berasal dari keanekaragaman hayati lokal. Oleh karena itu perlu dilakukan penelusuran dan dokumentasi secara lengkap untuk mendukung penelitian ilmiah selanjutnya menuju pengembangan obat asma modern dalam industri farmasi.

\section{METODE PENELITIAN}

Jenis penelitian ini adalah deskriptif kualitatif menggunakan metode wawancara. Sampel responden ditentukan berdasarkan teknik purposive sampling, yaitu dengan memilih responden yang memiliki keahlian melakukan pengobatan tradisonal suku Serawai. Teknik ini dipilih agar memperoleh data yang valid berdasarkan pengetahuan responden yang diturunkan secara turun menurun. Responden tersebut adalah lima orang dukun pengobatan tradisional (battra) suku Serawai di Kecamatan Sukaraja Kabupaten Seluma.

Variabel (objek) penelitian ini adalah pemanfaatan daun tanaman kemuning sebagai obat asma yang dilakukakan oleh masyarakat suku Serawai yang ada dikecamatan Sukaraja.
Pengumpulan data ini terdiri atas tahap persiapan, yaitu observasi lokasi penelitian, dan tahap pelaksanaan penelitian, yaitu wawancara dan dokumentasi. Wawancara dilakukan dengan mewawancarai dukun pengobatan tradisional (battra) dan masyarakat setempat yang menggunakan tumbuhan ini. Pedoman wawancara yang digunakan memuat daftar pertanyaan yang berupa garis-garis besar dari permasalahan. Tabel 1 merupakan kisi kisi yang digunakan sebagai pedoman wawancara.

Tabel 1. Kisi-Kisi Wawancara

\begin{tabular}{|l|l|}
\hline No & \multicolumn{1}{|c|}{ Indikator } \\
\hline 1 & $\begin{array}{l}\text { Dari mana pengetahuan mengenai } \\
\text { tumbuhan kemuning dapat dijadikan } \\
\text { sebagai obat asma ini berasal? }\end{array}$ \\
\hline 2 & $\begin{array}{l}\text { Dari mana memperoleh tumbuhan } \\
\text { kemuning yang dijadikan sebagai bahan } \\
\text { obat tradisional asma? }\end{array}$ \\
\hline 3 & $\begin{array}{l}\text { Bagian manakah dari tumbuhan } \\
\text { kemuning yang digunakan sebagai obat } \\
\text { asma? }\end{array}$ \\
\hline 4 & $\begin{array}{l}\text { Bagaimanakah cara mengolah tumbuhan } \\
\text { kemuning agar berkhasiat sebagai obat } \\
\text { asma? }\end{array}$ \\
\hline 5 & $\begin{array}{l}\text { Berapa lama pengobatan ini dilakukan } \\
\text { untuk menyembuhkan penyakit asma? }\end{array}$ \\
\hline 6 & $\begin{array}{l}\text { Apakah ada efek samping dari pemberian } \\
\text { daun kemuning sebagai obat asma? }\end{array}$ \\
\hline 7 & $\begin{array}{l}\text { Apakah penggunaan daun kemuning } \\
\text { sebagai obat asma perlu dipertahankan? }\end{array}$ \\
\hline
\end{tabular}

\section{HASIL DAN PEMBAHASAN}

Informasi mengenai pemanfaatan daun kemuning sebagai obat asma, yang digunakan masyarakat suku Serawai di kecamatan Sukaraja kabupaten Seluma, diperoleh dari wawancara dengan dukun kampung yang menggunakan daun kemuning sebagai obat asma. Lima narasumber yang diwawancarai adalah yang terbiasa mengobati masyarakat yang terkena penyakit dengan cara tradisional dan yang memiliki pengetahuan tentang pemanfaatan 
daun kemuning sebagai tumbuhan obat dengan baik yaitu, nenek Aan, ibu Nun Tiara Munif, Ibu Sri Sukis Yanti Andayani, ibu Sunarti, dan Ibu Rahmi Idawati. Responden yang diwawancarai ini memiliki pengetahuan mengenai pemanfaatan daun kemuning sebagai obat tradisional asma diperoleh dari orang tua, keluarga terdekat, dan teman. Pengetahuan ini diwariskan secara turun temurun dari generasi ke generasi.

Berdasarkan hasil wawancara yang telah dilakukan, diketahui bahwa masyarakat suku Serawai telah sejak lama menggunakan daun kemuning sebagai obat tradisional penyakit asma. Masyarakat juga telah membudidayakan tumbuhan kemuning di sekitar pekarangan rumah. Meskipun tidak mengidap penyakit asma, namun sebagian masyarakat menanam kemuning sebagai tanaman hias di rumah sehingga jika dibutuhkan dapat mengambil dari pekarangan rumah.

Bagian dari tumbuhan kemuning yang dimanfaatkan adalah bagian daunnya. Menurut Mattjik (2010), daun kemuning berwarna mengkilap, berbentuk oval, ujung lancip dengan panjang $5 \mathrm{~cm}$. Daun kemuning bersifat pedas, pahit dan hangat (Ayu, 2011), dan mengandung methyl anthranilat, beta caryophyllen, geraniol, carene-3, eugenol, citronellol, methyl salicylate,s-quaiazulena, osthol, peniculatin, coumurrayin, bisabolene, cadinene (Nugrahaningtiyas, 2019).

Daun kemuning yang digunakan sebagai obat asma adalah daun yang telah tua dengan ciri warna sudah hijau pekat. Daun diambil sebanyak segenggam tangan orang dewasa, lalu diremas dan ditambahkan sedikit air. Biasanya ditambahkan sedikit beras untuk memudahkan dalam proses peremasaan. Kemudian air perasan daun diambil dan ditambah madu untuk mengurangi rasa pahit, setelah itu langsung diberikan sebagai minuman kepada penderita asma sebanyak 1 sendok makan. Air perasan daun kemuning diminum pada pagi hari sebelum mengonsumsi makanan yang lain, dan dilakukan selama 3- 7 hari berturutturut.

Ramuan air perasan daun kemuning diberikan ketika penderita menunjukkan gejala seperti mengi dan batuk. Ramuan ini dapat diberikan pada semua kalangan usia, namun untuk pemberian pada balita dosis nya dikurangi menjadi 2-3 tetes saja. Ketika air perasan daun kemuning diminum akan menyebabkan muntah sebagai reaksi obat untuk mengeluarkan lendir yang menyumbat saluran pernapasan. Setelah penggunaan obat secara teratur selama kurun waktu 3-7 hari biasanya akan langsung terlihat perubahan yang signifikan ditandai dengan tidak adanya mengi dan batuk. Selain diminum, air perasan daun kemuning juga dapat dapat dioleskan didada atau di bagian kepala.

Pengobatan asma dengan menggunakan daun kemuning penting dipertahankan. Hal ini karena pengobatan asma menggunakan daun kemuning dinilai lebih aman digunakan, lebih ekonomis dan mudah didapat serta tidak memiliki efek samping yang dapat membahayakan tubuh.

\section{KESIMPULAN}

Pemanfaatan kemuning sebagai obat asma telah lama digunakan secara turun menurun oleh masyarakat suku Serawai Kecamatan Sukaraja Kabupaten Seluma. Bagian tanaman kemuning yang dimanfaatkan sebagai obat asma adalah organ daun. Daun tersebut diolah dengan cara diremas dan di ambil airnya untuk diminum atau dioleskan ke dada. Perlu 
dilakukan kajian lebih lanjut mengenai kandungan fitokimia pada daun kemuning, pengujian pra klinis dan klinis, sehingga dapat dikembangkan sebagai obat asma modern.

\section{DAFTAR PUSTAKA}

Ayu, P. (2011). Ragam Bunga Berkhasiat Obat. Yogyakarta: Cermerlang Publishing.

Global Intiative For Asthma (GINA). 2011. Global Strategy for Asthma Management for Preventation. www.ginasthma.org

Hembing, wijayakusuma. 2000. Ramuan Tradisional untuk pengobatan darah tinggi .Jakarta : Penebar Swada.

Iskandar, A. 2005. Mengatasi Gangguan Pencernaan Dengan Terapi Tradisional. Jakarta: Agromedia Pustaka.

Kinoshita, T., Tatara, S., Ho, F., \& Sankawa, U. (1989). 3-Prenylindole from Murraya paniculata and their biogenetic significance. Phytochemistry, 147-151.
Kinoshita,T., Wu, J.B., dan HO, F.C. 1996, Prenylcoumarins from Murraya paniculata var. ompphalocarpa (Rutaceae) : The Absolute Configuration of Sibirin, Mexotocin and Omphamurin. Chemical Pharmaceuitical Bulletin. 44 (6): 1208-1211.

Kong.T.C,Ng,K.H.,P.P,Li,Q.,Yu,S.X.,Zang, H.T.,Cheng, K. F., Soejarto,D.D., Kan,W.S.,Waterman,P.Y.,1986.Sourc e of the Anti-Implantation Alkaloid Youthuknee In the Genus Murraya,. J. of Ethanopharmacology,15:195200.

Mattjik, N. A. 2010. Murraya paniculata. P. 245. Dalam A. Purwito (Ed). Tanaman Hias dan Bunga Potong.Bogor: IPB Press.

Portal Selumakab. Sejarah Kabupaten Seluma.Portal.selumakab.go.id.

https://portal.selumakab.go.id/sejarah -singkat/

World Health Organization. An Expanded DOTS Framework for effective Tuberculosis Control. Geneva. World Health Organizaton, 2002. 